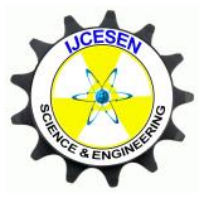

Copyright (C) IJCESEN
International Journal of Computational and

Experimental Science and Engineering

(IJCESEN)

Vol.5 -No.2 (2019) pp. 65-68

http://dergipark.org.tr/ijcesen

Research Article

\title{
Reactive Compatibilization of Poly(lactic acid) and Polycarbonate Blends Through Catalytic Transesterification Reactions
}

\author{
Nadjat CHELGHOUM, Melia GUESSOUM* and Nacerddine HADDAOUI \\ Laboratoire de Physico-Chimie des Hauts Polymères (LPCHP), Département de Génie des Procédés, Faculté de \\ Technologie, Université Ferhat ABBAS Sétif-1, Sétif (Algeria) \\ * Corresponding Author : guessoum_melia@yahoo.fr \\ ORCID: 0000-0003-0392-5538
}

\section{Article Info: \\ Keywords \\ Transesterification \\ Compatibilization \\ Catalyst \\ Nanocomposite}

DOI: $10.22399 /$ ijcesen. 478143

Received : 02 November 2018

Accepted : 15 July 2019

\begin{abstract}
The combination of poly(lactic acid) (PLA) with polycarbonate (PC) which presents high inherent thermal stability and mechanical properties is an attractive strategy to overcome PLA brittleness and poor thermal resistance. To improve affinity between the two materials and their dispersion into the blend, an organophilic montmorillonite (MMT) has been added and reactive compatibilization through catalyzed transesterification has been investigated. The properties were studied using differential scanning calorimetry (DSC), thermogravimetry (TG), dynamic mechanical analysis (DMA) and scanning electron microscopy (SEM). The study of the thermal properties revealed the immiscibility of the uncatalyzed blend but noticeable changes were detected on the PLA crystallization and melting behaviors after the addition of the catalyst. The SEM observations showed that MMT and the catalyst contribute in the improvement of the dispersion. The TG results revealed that MMT increases the thermal stability of the blend and showed new stages of decomposition due to the different structures resulting from the interchange reactions.
\end{abstract}

\section{Introduction}

To improve the properties of poly(lactic acid)/polycarbonate (PLA/PC) blend, several methods have been tried through different strategies of compatibilization such as the addition of compatibilizers or the use of catalyzed transesterification reactions [1]. To promote the insitu synthesis of copolymers at the interface between PLA and PC, various catalysts have been used in particular monobutyltin oxide [2], tetrabutylorthotitanate [3], tetrabutyl ammonium tetraphenyl borate [4] and samarium acetylacetonate (Sm-Acac) [5]. Besides, studies have shown that the addition of nanofillers can be a new and efficient strategy for stabilizing the morphology of immiscible polymers blends $[6,7]$. The nanoparticles compatibilizing effect depends mainly on their selective affinity for the matrix or the dispersed phase and as for compatibilizers, the particles at the interface reduce the interfacial tension and prevent the dispersed nodules coalescence [8].
In this work, the properties of PLA/PC blends and nanocomosites were studied in the presence of both a catalyst which is $\mathrm{Sm}$ (Acac) and an organophilic montmorillonite (MMT), to demonstrate their contributions in the compatibilization of the system.

\section{Experimental}

\subsection{Materials and Processing}

PLA is a PLI 005 resin of Nature Plast. PC which is Makrolon 2858 is supplied by Bayer. The Sm-Acac catalyst $\left(\left(\mathrm{C}_{5} \mathrm{H}_{8} \mathrm{O}_{2}\right)_{3} \mathrm{Sm}_{\mathrm{xH}} \mathrm{O}\right)$ is a Sigma-Aldrich product. The MMT, nanomer 1.34TCN of nanocor, is modified with bis-(2-hydroxyethyl) methyl tallow alkylammonium. (50/50) PLA/PC blends and (50/50/3) PLA/PC/MMT nanocomposites were prepared without and with $0.25 \%$ of Sm-Acac in a Brabender plasticorder for $15 \mathrm{~min}$ at $220^{\circ} \mathrm{C}$ and a mixing speed of $30 \mathrm{rpm}$. 


\subsection{Characterization Methods}

Differential scanning calorimetry (DSC) analysis was carried out on a Perkin-Elmer instrument. Samples were heated from 25 to $250^{\circ} \mathrm{C}$ at $10^{\circ} \mathrm{C} / \mathrm{min}$, cooled to $25^{\circ} \mathrm{C}$ then reheated to $250^{\circ} \mathrm{C}$ at $10^{\circ} \mathrm{C} / \mathrm{min}$. Dynamic mechanical analysis (DMA) was achieved on a TA instrument, at a frequency of $1 \mathrm{~Hz}$ and by heating the samples up to $180^{\circ} \mathrm{C}$ at $3^{\circ} \mathrm{C} / \mathrm{min}$. Thermogravimetric analysis (TGA) was performed by heating the samples from 25 to $700^{\circ} \mathrm{C}$ at $10^{\circ} \mathrm{C} / \mathrm{min}$ using a Perkin Elmer TGA 4000 . Morphology was observed on a JSM-6301F electron microscope.

\section{Results and Discussion}

\subsection{Thermal properties and microstructure analysis}

Figs. 1 and 2 show the DSC and DMA thermograms of PLA, PC and their uncatalyzed and catalyzed blends and nanocomposites. PLA presents a glass transition temperature $\left(\mathrm{T}_{\mathrm{g}}\right)$ around $59.2^{\circ} \mathrm{C}$, a crystallization peak between 80 and $135^{\circ} \mathrm{C}$ and two melting endotherms close to 150.5 and $156^{\circ} \mathrm{C}$ owing to two different crystalline populations. $\mathrm{PC}$ thermogram reveals a $\mathrm{T}_{\mathrm{g}}$ at $145^{\circ} \mathrm{C}$. After mixing with PC, the $\mathrm{T}_{\mathrm{g}}$ of the PLA phase is unchanged due to the blend immiscibility. But after adding the catalyst, the PLA $\mathrm{T}_{\mathrm{g}}$ and melting temperatures decrease contrary to the crystallization exotherm which shifts to higher temperatures due to the PLA reduced aptitude to crystallization resulting from the transfer of bulky PC units [5].

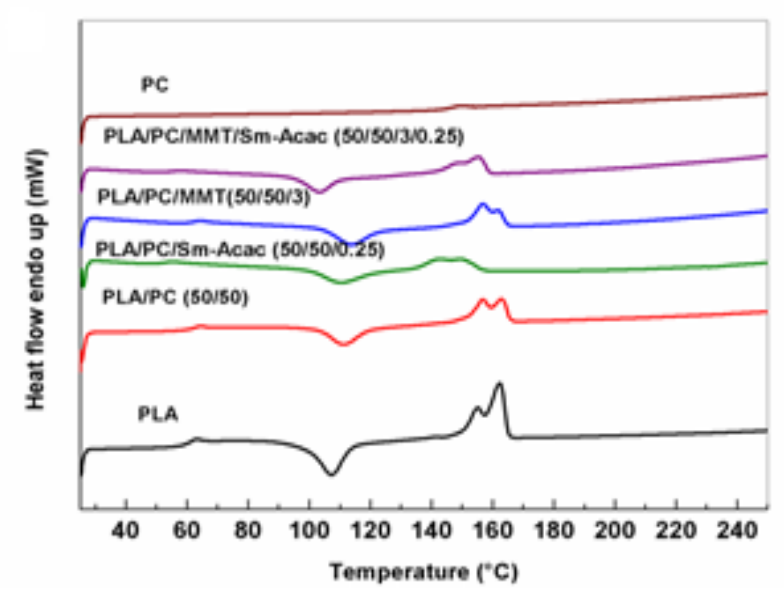

Figure 1. DSC thermograms of uncatalyzed and catalyzed blends and nanocomposites

The addition of $3 \%$ of MMT to the uncatalyzed blend causes a slight increase in the crystallization temperature due to the disturbing effect of the

nanoclay. However, in presence of the catalyst, the $\mathrm{T}_{\mathrm{g}}$ and crystallization and melting temperatures vary notably due to the effects of MMT nanoparticles and PC units on the PLA crystallization process.

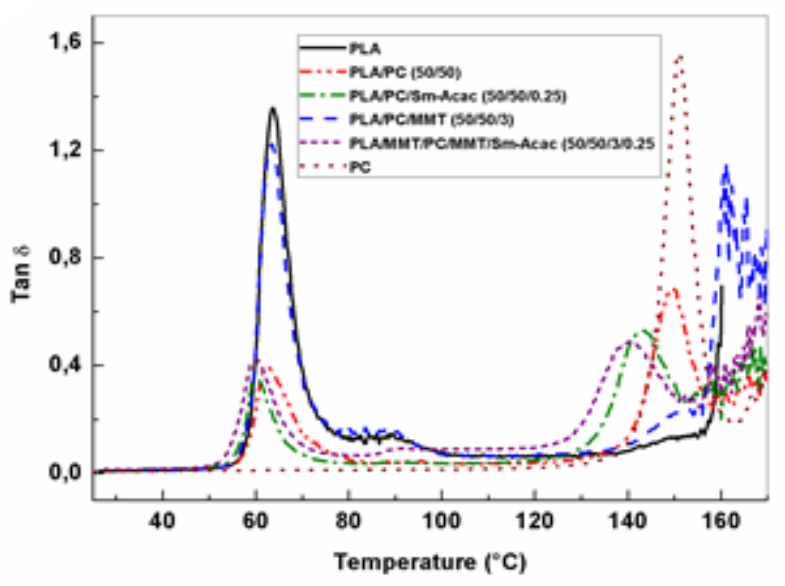

Figure 2. DMA thermograms of uncatalyzed and catalyzed blends and nanocomposites

The micrographs given by Figs. $3 a$ and $3 b$, representing, respectively, the uncatalyzed and catalyzed (50/50) PLA/PC systems, show a cocontinuous morphology due to the similar proportions of the two polymers into the blends, with a better adhesion in presence of the catalyst.

(a)

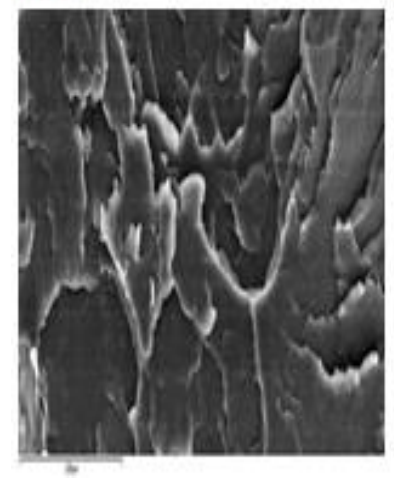

(c)

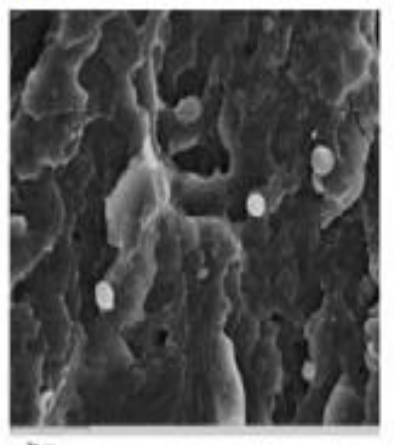

Figure 3. SEM micrographs of uncatalyzed and catalyzed PLA/PC blends and nanocomposites: (50/50) (a), (50/50/0.25) (b), (50/50/3) (c), (50/50/3/0.25) (d)

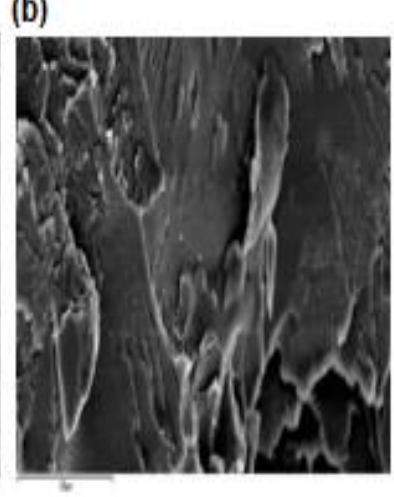

(d)

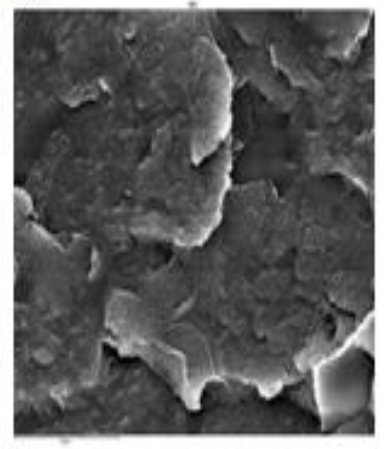


After the addition of 3\% of MMT, the cocontinuous morphology (Fig. 3c) is still observed but the dispersion of the two polymers seems better. The refinement of blends morphology due to clays is explained by the decrease in the interfacial energy and the inhibition of coalescence [7, 8].

The micrograph (Fig.3d) of the nanocomposite shows a co-continuous morphology in which the PLA and PC phases are not pure but contain small nodules due to a better dispersion. The refinement of the size of the nodules of the dispersed phase in the presence of an organomodified clay relative to the mixtures has already been reported by As'Habi et al. [8] who explained that this could be due to the decreased interfacial energy and inhibition of coalescence due to the presence of a solid barrier around the nodules.

\subsection{Thermal stability}

Figs. $4 \mathrm{a}$ and $4 \mathrm{~b}$ show the TG and DTG thermograms of PLA, PC and their blends and nanocomposites. The blends thermograms exhibit two steps due to the decomposition of PLA and PC phases.

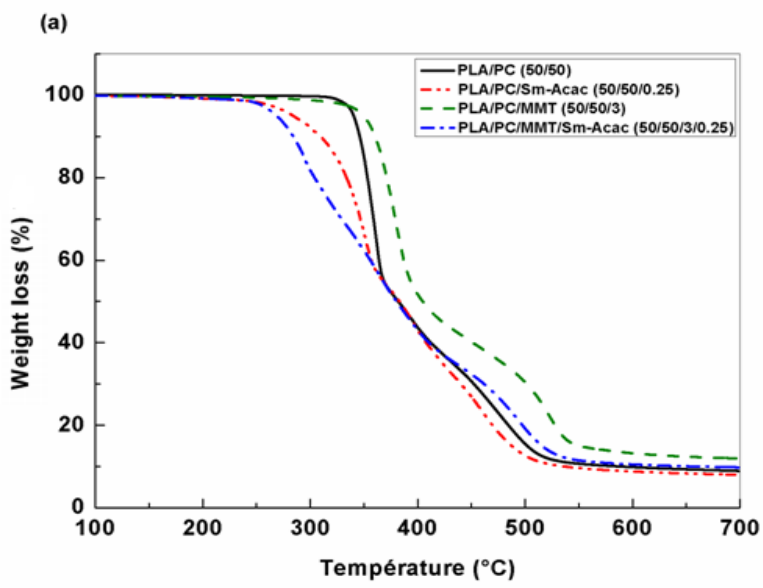

(b)

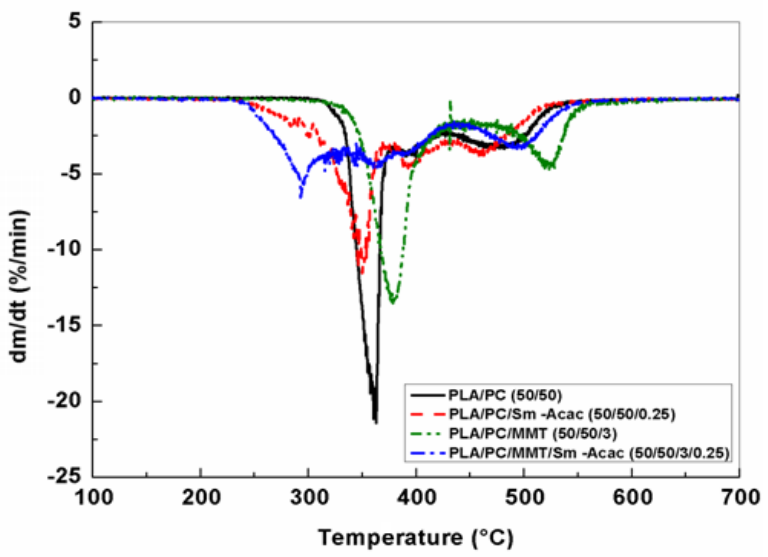

Figure 4. TG (a) and DTG (b) thermograms of uncatalyzed and catalyzed blends and nanocomposites
In these blends, the degradation temperature of the PC phase is shifted to a lower value because of the accelerating effect exerted by the decomposition of the PLA phase which residues decrease the PC thermal stability [4].

After adding the catalyst, the blend reveals a third degradation stage which supports the presence of a copolymer phase presenting a structure close to those of the homopolymers.

The uncatalyzed PLA/PC/MMT nanocomposite decomposes in two stages but shows a higher thermal stability due to the MMT which forms a thermally stable-char that delays the polymers degradation. However, in presence of the catalyst, the nanocomposite exhibits four stages of decomposition with different characteristics owing to the degradation of the catalyst, the surfactant and new copolymer structures resulting from Sm-Acac catalyzed interchanges reactions between the two polyesters.

\section{Conclusion}

The synergetic combination of the nanoclay and insitu synthesis of copolymer structures into the interfacial region between PLA and PC phases allowed a considerable change of the blend microstructure, resulting in an improvement of its thermo-rheological properties and thermal stability.

The transreactions between the two polymers are well evidenced by the supplementary stages of decomposition and the $\mathrm{T}_{\mathrm{g}}$ variations of PC and PLA phases into the catalyzed blend and nanocomposite. Also, it was concluded that the PLA crystallization behavior has been greatly inhibited due to the presence of MMT and PC units that were inserted into the PLA chains due to interchanges between the two polymers. This caused chains mobility restrictions and prevented their ordering into crystals.

\section{References}

[1] Y. Chen, , Y. Peng, W. Liu, G. Zeng, J. Yang, X. Yan, The effect of various catalyzers on transesterification in reactive blending PC/PLA blends, Advanced Materials Research 741(2013) 2427. DOI :10.4028/www.scientific.net/AMR.741.24

[2] Y. Zhou, L. Luo, W. Liu, Y. Chen, Preparation and characteristic of PC/PLA/TPU blends by reactive extrusion, Advances in Materials Science and Engineering 6(2015) 1-9

[3] C. Liu, S. Lin, C. Zhou, W. Yu, Influence of catalyst on transesterification between poly(lactic acid) and 
polycarbonate under flow field, Polymer 54(2013) 310-319.DOI: 10.1016/j.polymer.2012.11.047

[4] V.T. Phuong, M.B. Coltelli, P. Cinelli, M. Cifelli, S. Verstichel, A. Lazzeri, Compatibilization and property enhancement of poly(lactic acid)/polycarbonate blends through triacetinmediated interchange reactions in the melt, Polymer 55(2014)4498-4513.DOI:10.1016/j.polymer. 2014. 06.070

[5] N. Chelghoum, M. Guessoum, M. Fois, N. Haddaoui, Contribution of catalytic transesterification reactions to the compatibilization of PLA/PC blends: thermal, morphological and viscoelastic characterization, Journal of Polymers and the Environment 26 (2018) 342-354. DOI: 10.1007/s10924-017-0950-4

[6] Y. Wang, Q. Zhang, Q. Fu, Compatibilization of immiscible poly(propylene)/polystyrene blends using clay», Macromolecular rapid communications, 24(2003)231-235.DOI: 10.1002/marc.200390026

[7] J. S. Hong, Y. K. Kim, K. H. Ahn, S. J. Lee, C. Kim, Interfacial tension reduction in $\mathrm{PBT} / \mathrm{PE} /$ clay nanocomposite, Rheological Acta 46(2007)469478.DOI:10.1007/s00397-006-0123-1

[8] L. As'habi, S.H. Jafari, H.A. Khonakdar, R. Boldt, U. Wagenknecht, G. Heinrich, Tuning the processability, morphology and biodegradability of clay incorporated PLA/LLDPE blends via selective localization of nanoclay induced by melt mixing sequence. Express Polymer Letters. 7(2013) 2139.DOI: 10.3144/expresspolymlett.2013.3 